\title{
FRONTEIRA AGROPECUÁRIA COMO FATOR DO DESEMPENHO AMBIENTAL DA PISCICULTURA EM RONDÔNIA
}

\author{
Aurélio Ferreira Borges ${ }^{1}$ \\ Maria dos Anjos Cunha Silva Borges ${ }^{2}$ \\ José Luiz Pereira de Rezende ${ }^{1}$ \\ Valdemir Lúcio Durigon ${ }^{3}$ \\ José Ribamar de Oliveira ${ }^{4}$ \\ Aquiles da Silva Santos ${ }^{4}$ \\ Carlos Henrique dos Santos ${ }^{4}$
}

Resumo: A ocupação do espaço territorial brasileiro proporciona padrões amostrais que a literatura define como "frentes". Esta fronteira agropecuária se caracteriza pelo deslocamento de transformações territoriais, com base na inserção de novas tecnologias. Com a presente pesquisa pretende-se conhecer o processo de expansão da aquicultura em Rondônia, partindo do pressuposto de que o avanço da aquicultura influencia no desempenho ambiental do meio rural. O levantamento bibliográfico e a análise de dados documentais permitiram a caracterização do avanço da aquicultura continental. Verificou-se que o ímpeto desta ocupação é evidente nos assentamentos implantados, sobretudo, ao longo da BR 364, numa faixa marginal de 100 quilômetros. Os imóveis rurais no estado de Rondônia foram criados tomando-se como fundamento áreas de 50 a 100 hectares. A produção aquícola acaba por avançar sobre a área de florestas protegidas pela legislação ambiental brasileira, provocando a avaria e a destruição desse ecossistema amazônico.

Palavras-chave: Expansão Espacial; Políticas Públicas; Legislação Ambiental; Amazônia Brasileira.

\footnotetext{
1 Universidade Federal de Lavras (UFLA). Departamento de Ciências Florestais, laboratório Lemaf. E-mails: aferreiraborges@gmail.com, jlprezen@ufla.br.

${ }^{2}$ Senai-RO. E-mail: maria.cunhaborges@gmail.com.

${ }_{3}^{3}$ Universidade Federal Rural do Rio de Janeiro. E-mail: mariasocorrodurigon@yahoo.com.br.

4 Instituto Federal de Educação de Rondônia, Câmpus Colorado do Oeste-RO. E-mails: ribamar@ifro.edu.br, aquiles.silva@ifro.edu.br, carlos.henrique@ifro.edu.br.
}

Revbea, São Paulo, V. 9, N 1: 43-55, 2014.

revista brasileira educação ambiental 


\section{Introdução}

De acordo com a História, o território brasileiro foi tomado do litoral para o interior, e esta metodologia de ocupação "sertão adentro" recebeu o nome de expansão de fronteiras, caracterizado por distintas "frentes" (SILVA; MIZIARA, 2011). Segundo os autores, este método de ocupação caracterizouse pelo pragmatismo e imediatismo, onde a preservação da vegetação original sempre esteve relegada a um segundo plano. Em Rondônia, a agropecuária apareceu como o fundamento deste processo de instalação da Frente Pioneira, quando da ocupação inicial do território, e da Frente de Expansão, referente ao uso capitalista da terra, sobretudo a partir do início da década de 1970 do século $X X$, com a crescente intensificação da ocupação, bem como uma ascendente assimilação capitalista da terra.

Conforme Silva (2008), o estado de Rondônia é caracterizado pela concentração de grandes áreas reservadas à preservação através das Unidades de Conservação (UC) e Terras Indígenas (TI) que perfazem uma área total de $90.301,6 \mathrm{Km}^{2}$, representando $38 \%$ da área total do estado. As Unidades de Conservação estão distribuídas num total de 54, sendo uma Área de Proteção Ambiental, cinco Estações Ecológicas, onze Florestas Estaduais de Rendimento Sustentável, três Florestas Nacionais, três Parques Estaduais, dois Parques Nacionais, quatro Reservas Biológicas e 25 Reservas Extrativistas, somando um total de $53.153 \mathrm{Km}^{2}, 22,4 \%$ do estado. Deste conjunto, 41 é de domínio estadual e 13 federal recobrindo o território em 21.681 e $31.472 \mathrm{Km}^{2}$, respectivamente. Segundo a classificação do SNUC (Sistema Nacional de Unidades de Conservação) 40 são de uso sustentável e 14 de proteção integral somando 24.384 e $28.769 \mathrm{Km}^{2}$ respectivamente.

As Terras Indígenas estão distribuídas em 28 áreas somando um total de $51.415 \mathrm{Km}^{2}$. Existem três áreas de sobreposição entre terras indígenas e unidades de conservação demonstrando um problema fundiário que deve ser tratado com maior atenção. Reflexo de uma ocupação recente, o estado apresenta uma concentração desta ocupação ao longo da principal rodovia, a BR 364, que corta Rondônia de sul a norte tomando uma nova direção a partir de Porto Velho para o Acre. O mosaico de imagens de satélite apresentado na Figura 1 mostra bem esta ocupação ao longo da rodovia e já um avanço em direção às áreas de fronteira internacional. Esta ocupação foi impulsionada a partir da década de 1970 do século XX, por políticas de governo que promoveram no estado a criação de projetos de assentamentos. 


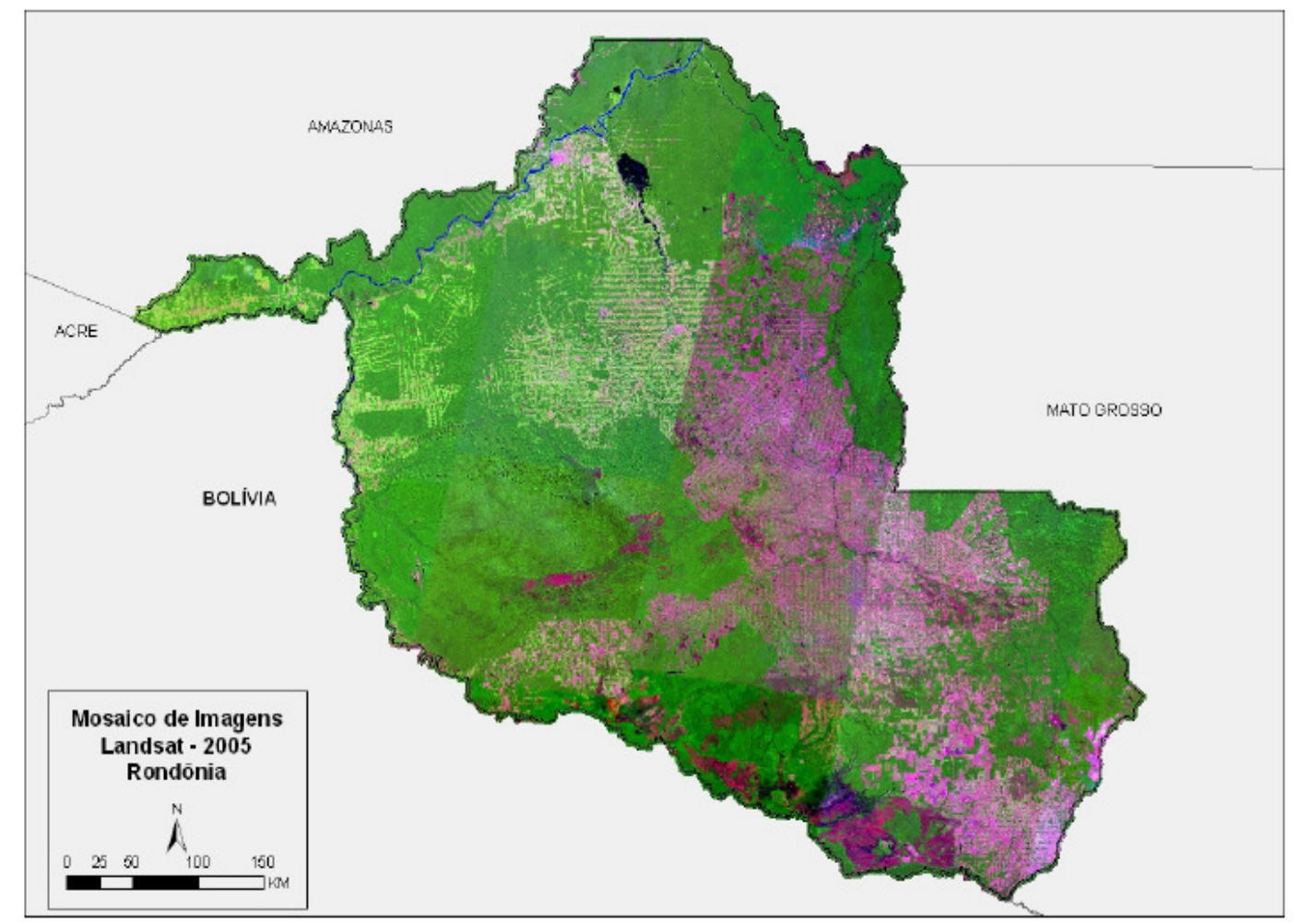

Figura 1: Mosaico de imagens do estado de Rondônia.

Fonte: Silva (2008).

O primeiro Plano Nacional de Desenvolvimento (1972 a 1974) fazia parte do período conhecido como milagre brasileiro e incorporou o Plano de Integração Nacional e o recém-criado Programa de Redistribuição de Terra e de Estímulo à Agroindústria do Norte e Nordeste (PROTERRA). Foi, desta forma, direcionado com o conjunto de políticas que já vinham sendo ampliadas nos moldes do discurso geopolítico da Escola Superior de Guerra (ESG) da década de 1950 do século XX, na acepção de que a área precisaria ser "desenvolvida" e "ocupada" e assim não suscitar "riscos" à segurança nacional (SCHRÖDER, 2008).

Essas medidas faziam parte da estratégia do governo de integrar a região à economia nacional, mesmo sendo controversas, no sentido que, ao mesmo tempo em que buscavam integrar, também isolavam e discriminavam as regiões a serem integradas, conforme Lei $n^{\circ} 5.727$, de 04 de novembro de 1971: realizar-se-á a integração de sentido Leste-Oeste, principalmente para permitir a associação destes fatores relativamente abundantes nas duas áreas: no Nordeste, mão de obra não qualificada, e na Amazônia, Planalto Central, terra e outros recursos naturais (BRASIL, 1971). Para essa lei que criou o Plano Nacional de Desenvolvimento (PND), a Amazônia era concebida como uma região de fronteira, pois era considerada uma área de expansão da 
fronteira econômica, para absorver os excedentes populacionais de outras áreas e com isso buscar elevar o coeficiente de renda e bem estar da região.

De acordo com o Relatório Final do Projeto Gestão Territorial e Desenvolvimento Sustentável (GTDS, 2006), apesar da ação do Estado parecer coordenada para estudar os recursos potenciais da região, as preocupações com a ocupação e a defesa do território brasileiro não foram esquecidas.

O Instituto Nacional de Colonização e Reforma Agrária (INCRA), através de suas atribuições e em cumprimento à legislação, estabeleceu dois modelos de assentamento em Rondônia, os Projetos Integrados de Colonização (PIC) e os Projetos de Assentamento Dirigido (PAD). Ambos possuíam a forma de espinha de peixe, com estradas coletoras de até cem quilômetros, partindo dos eixos rodoviários e, das estradas coletoras construíam-se novas estradas perpendiculares e retilíneas, denominadas linhas (SCHRÖDER, 2008).

Segundo esse autor, O POLONOROESTE (Programa Integrado de Desenvolvimento do Noroeste) foi um programa financiado pelo Banco Mundial e tinha como principal objetivo o atendimento à região do entorno da rodovia Cuiabá-Porto Velho. Essa preocupação na criação do programa se deu devido ao intenso fluxo migratório, com ocupação espontânea e desordenada da região, e com a incapacidade do governo de dar um correto ordenamento e também o apoio socioeconômico às populações que chegavam ao território. Esse Programa também não atingiu todos os seus objetivos propostos principalmente em relação a um processo de desenvolvimento que fosse capaz de assegurar o crescimento econômico com sustentabilidade ambiental. $O$ prenúncio da fase final do POLONOROESTE era a razão primordial para se empreender o zoneamento socioeconômico e ecológico de Rondônia, que funcionaria para orientar e fundamentar as bases de um novo plano, elaborado sob a orientação do Banco Internacional para Reconstrução e Desenvolvimento (BIRD) e desta vez denominado PLANAFLORO. Conforme Schröder (2008), desta forma, finaliza-se o POLONOROESTE e, com a entrada do PLANAFLORO, constitui-se o sentido de urgência que havia em dar continuidade aos planos de desenvolvimento para o estado de Rondônia (Tabela 1). 
Tabela 1: Zoneamento socioeconômico e ecológico de Rondônia, segundo zona, destinação, finalidade e área.

\begin{tabular}{|c|c|c|c|c|}
\hline ZONA & DESTINAÇÃO & FINALIDADE & $\begin{array}{l}\text { ÁREA } \\
\text { (ha) }\end{array}$ & $\%$ \\
\hline 1 & $\begin{array}{l}\text { Exploração } \\
\text { agropecuária }\end{array}$ & $\begin{array}{l}\text { Ordenamento e recuperação das atividades } \\
\text { agrícolas, pecuárias e agroflorestais. }\end{array}$ & 6.195 .000 & 28 \\
\hline 2 & $\begin{array}{l}\text { Pequenos } \\
\text { produtores }\end{array}$ & $\begin{array}{l}\text { Recuperação e desenvolvimento da } \\
\text { atividade agropecuária e de agricultura } \\
\text { consorciada com culturas permanentes. }\end{array}$ & 3.015 .000 & 13,5 \\
\hline 3 & Ribeirinha & $\begin{array}{l}\text { Aproveitamento de várzeas e terras firmes } \\
\text { marginais aos rios, desenvolvendo } \\
\text { atividades agroflorestais e pesqueiras. }\end{array}$ & 589.000 & 2,6 \\
\hline 4 & Extrativista & $\begin{array}{l}\text { Ordenamento e desenvolvimento do } \\
\text { extrativismo vegetal de castanha, gomas, } \\
\text { óleos, frutos e raízes exploráveis. }\end{array}$ & 3.500 .000 & 15,9 \\
\hline 5 & Manejo Florestal & $\begin{array}{l}\text { Importante potencial madeireiro para } \\
\text { extração em escala comercial. }\end{array}$ & 2.435 .000 & 11 \\
\hline 6 & $\begin{array}{l}\text { Conservação e } \\
\text { preservação }\end{array}$ & $\begin{array}{l}\text { Garantir a manutenção dos ecossistemas e } \\
\text { o equilíbrio ecológico. }\end{array}$ & 6.400 .000 & 29 \\
\hline
\end{tabular}

Fonte: adaptado de SCHRÖDER (2008).

\section{Histórico das Áreas de Preservação Permanente e suas características técnicas no entorno de represas, açudes e tanques para peixes}

A partir do ano de 1934 começam as primeiras ideias e registros da legislação voltados às questões ambientais do território brasileiro. O DecretoLei no 23.793, que aprovou o Código Florestal de 1934 (BRASIL, 1934a) e o Decreto n 24.643, que instituiu o Código das Águas (BRASIL, 1934b), são desígnios legais que procuraram estabelecer os possíveis e diferentes usos das águas e das florestas protetoras, bem como sua propriedade. Verifica-se nestas normas jurídicas o ponto de partida oficial do compromisso ecológico do Estado e da população. Este Código proporcionava determinadas peculiaridades preservacionistas, situando o uso da propriedade rural em função do tipo florestal existente, procurando definir as classes de florestas protetoras, remanescentes, padrão e de rendimento. As florestas protetoras apresentavam, para a época, um indício do que seria o instituto das florestas de preservação permanente, instituído pelo Código Florestal de 1965. Mesmo assim, a ideia e, ou, o espírito do Código Florestal de 1934 já era extremamente conservacionista (BORGES et al.2011).

Segundo esses autores, logo em 1965, com a publicação do Segundo Código Florestal (BRASIL, 1965), o clássico Código Florestal de 1934 foi aprimorado. Este novo Código representou importante instrumento disciplinador das atividades florestais ao declarar as florestas existentes no território nacional como bens de interesse comum a toda a população e limitou o uso da propriedade rural por seus proprietários. A Lei № 9.433 de 1997, 
(BRASIL, 1997) vinculou, claramente, as questões dos Recursos Hídricos com as questões ambientais. Dentro desse princípio, não pode ser desconsiderado que a água é, também, matéria-prima do sistema produtivo agropecuário.

Atualmente, por influência da sociedade, conflitos e explicações imprecisas, essas áreas de proteção passaram a serem chamadas de Áreas de Preservação Permanente (APPs) e Áreas de Reserva Legal, denominadas florestas protetoras. Essas modificações foram editadas pela Medida Provisória (MP) 2.166-67 de 2001 (BRASIL, 2001). As florestas protetoras estão acopladas absolutamente às funções ambientais, por meio do provimento de bens e serviços essenciais para toda a população. Esses bens e serviços estão relacionados à retenção de sedimentos, regularização da vazão da água, recarga do lençol freático, conservação do solo, biodiversidade, ecoturismo, entre outros.

A interpretação ecológica das florestas protetoras deve incluir, além dos aspectos ambientais, também os aspectos econômicos, sociais e culturais, considerados aspectos relevantes para a melhoria da qualidade da vida humana (BORGES et al., 2011). Na perspectiva dos autores, a legislação federal deverá ter um caráter geral, objetivo e exequível. Deve ser respeitada pelos estados e municípios, conforme competência concorrente definida pela Constituição Federal de 1988, e só poderá ser alterada de acordo com os valores associados de cada floresta protetora. Essas alterações devem ser no intuito de alargar as restrições gerais, seguindo assim as peculiaridades e condicionantes de cada local. Este fato está embasado na Constituição Federal do Brasil de 1988 (BRASIL, 1988).

A Lei o 1.861 de 2008 (BRASIL, 2008) que dispõe, define e disciplina a piscicultura no estado de Rondônia estabeleceu que fosse declarada de interesse social e econômico a atividade de piscicultura para fins de implantação em aproveitamento de Área de Preservação Permanente já antropisada, atendidos os requisitos estabelecidos nesta lei (BRASIL, 2008). Essa lei estabeleceu que, nas suas relações com o meio ambiente, no Art. 5o é declarada de interesse social e econômico a atividade de piscicultura para fins de implantação em aproveitamento de Área de Preservação Permanente já antropisada, atendidos os requisitos estabelecidos nesta lei. No parágrafo $1^{\circ}$ desse mesmo artigo estabeleceu que: a construção de reservatórios de água, represas, açudes e tanques usados para implantação de atividade de piscicultura poderá ser licenciada nos cursos de água com vazão média máxima de $1 \mathrm{~m}^{3}$ (um metro cúbico) por segundo. Essa mesma lei estabeleceu que fosse autorizada pela Secretaria de Estado do Desenvolvimento Ambiental (SEDAM), a implantação da atividade de piscicultura em florestas protetoras que irregularmente foram subtraídas para dar lugar a pastagens e outras atividades agropecuárias quando o requerente: Artigo $6^{\circ}$, Inciso I - comprovar a imprescindibilidade da intervenção na floresta protetora para a viabilidade econômico-financeira total do empreendimento; II - comprovar o acompanhamento técnico de profissionais habilitados em área acima de dois hectares para condução dos projetos de engenharia (obras de arte) e ou do 
licenciamento ambiental; VI - apresentar projeto de recuperação da mata ciliar com afastamento máximo de 20 metros a partir da bordadura dos reservatórios obedecendo ao que dispõe o Art. 2º da Lei Federal 4.771, de 1965.

A literatura científica levantada por METZGER (2010) e por BORGES et al. (2011) mostra que a redução do grau de exigência preservacionista dessas áreas por meio das normas jurídicas poderia trazer graves prejuízos ao patrimônio biológico e genético brasileiro.

A presença e o desempenho das funções ambientais e hidrológicas das florestas protetoras ao redor dos reservatórios de água, represas, açudes e tanques usados para implantação de atividade de piscicultura naturais ou artificiais permitem manter a estabilidade da bacia hidrográfica. O projeto apropriado de utilização do solo e, em alguns acontecimentos, a restrição de uso de parte da bacia hidrográfica, é que serão essenciais para a preservação ambiental e manutenção da produção de água pela bacia.

O processo de construção de uma barragem altera toda a estrutura e característica do ambiente aonde irá se instalar o represamento, diferentemente do ambiente que caracteriza os reservatórios originais e naturais. O processo de represamento transforma o ambiente alterando os meio físico, biótico e, também, o socioeconômico, com reflexos a curto, médio e longo prazo (BORGES, 2008). A nova Área de Preservação Permanente que surge resultante da construção de um açude ou tanque escavado para a piscicultura é estabelecida em uma superfície geológica e biologicamente não preparada para essa situação, em que a estrutura do solo, a fauna e a vegetação originais não estão adaptadas às áreas ribeirinhas. Por serem ambientes instáveis e precários, sofrem processos de assoreamento, erosão, obstrução compactação e percolação, além dos relacionados com o caminho hidrológico nas camadas freáticas.

As barragens, açudes e tanques escavados para a piscicultura geram a deposição gradual de sedimentos, que são carreados para seu leito, em decorrência da deficiência e ausência da cinta vegetal de áreas representativas dos ecossistemas naturais de um determinado ambiente, concebida pelas florestas protetoras. Dentre os impactos ambientais, 0 assoreamento apresenta-se como um dos fundamentais problemas que comprometem barragens, açudes e tanques escavados para a piscicultura, uma vez que enfraquece a sua capacidade de acúmulo de água, inviabilizando sua operação, além de outras razões de problemas ambientais. $O$ acolhimento a essas florestas protetoras torna-se importante fator atenuante das forças erosivas e, no domínio natural de passagem de rudimentos do meio terrestre para o aquático, pois a ininterrupção de atividades antrópicas nessas florestas protetoras compromete, de maneira irreversível, o curso de bens e serviços fornecidos pelo meio ambiente.

Com a evolução da questão ambiental e das condições que o planeta apresenta o cultivo racional de organismos aquáticos, a aquicultura apresenta- 
se como atividade economicamente emergente na competição pelo recurso água (ELER; MILANI, 2007). Atualmente, a aquicultura enfrenta o desafio de moldar-se ao conceito de sustentabilidade, o que implica em agregar novos valores à produção de conhecimento e às práticas do setor.

$\mathrm{Na}$ perspectiva desses autores, apesar dos benefícios sociais, tais como geração de emprego e melhorias econômicas, deve-se considerar que todas as atividades produtivas são impactantes ao meio ambiente. Especialmente quando executadas de maneira inadequada e sem considerar os princípios básicos de alteridade socioambiental, dentre os quais, o planejamento do uso de recursos naturais e as estratégias que assegurem o desenvolvimento pretendido. Assim, dificilmente um princípio ou uma causa terá adquirido tanta adesão e consenso.

\section{Metodologia para determinação do desempenho ambiental da piscicultura}

Em pesquisa realizada em Rondônia, no município de Colorado do Oeste, BORGES et al. (2013a) entrevistaram amostra composta por 15 piscicultores, correspondentes a $26,31 \%$ do total de 57 piscicultores assessorados pela Empresa de Assistência Técnica e Extensão Rural de Rondônia (EMATER-RO). Para a coleta de dados foram realizadas entrevistas estruturadas, feitas através da aplicação de questionário. O questionário para realizar a avaliação do desempenho ambiental nas propriedades produtoras de peixe buscou uma aproximação teórica ao nível de sustentabilidade que tem os produtores para poder valorar seu desempenho ambiental (CARRASCO, 2006).

O questionário foi analisado em forma independente para cada propriedade produtora de peixes e através da seguinte fórmula foi determinado o coeficiente de sustentabilidade da propriedade produtora de peixes = (Quadros Verdes x 100) / (Total de Perguntas menos os Quadros amarelos). As perguntas do questionário foram geradas para dar atendimento a cada um dos itens anteriores, dando ao estudo um nível de requisitos internacionais. As 66 perguntas foram agrupadas em 12 (doze) itens. A seguir estão exemplos das perguntas do questionário utilizado na pesquisa, conforme Carrasco (2006). a) Esta propriedade tem licença de operação da fazenda? (O licenciamento ambiental para a aquicultura, no domínio Federal, tem o Instituto Brasileiro do Meio Ambiente e dos Recursos Naturais Renováveis (IBAMA) como órgão competente e obedece à legislação ambiental pertinente? b) Esta propriedade ocupa áreas de preservação ambiental permanente? c) 0 piscicultor possui registros que permitam saber que insumos e tratamentos receberam cada lote de peixes?

A mensuração da classificação da sustentabilidade das propriedades 
ambientalmente de todas as propriedades produtoras e categorização da sustentabilidade (Tabela 2).

Tabela 2: Classificação do desempenho ambiental para Colorado do Oeste, 2011.

\begin{tabular}{cc}
\hline CRITÉRIO & CLASSIFICAÇÃO \\
\hline Inferior a $30 \%$ & Crítica \\
\hline Entre 30 e $50 \%$ & Péssima \\
\hline Entre 50 e $70 \%$ & Adequada \\
\hline Entre 70 e $90 \%$ & Boa \\
\hline Superior a $90 \%$ & Excelente \\
\hline
\end{tabular}

Fonte: adaptado de Carrasco (2006)

A Figura 2 mostra a aproximação aos coeficientes de desempenho ambiental das propriedades avaliadas na amostra $(n=15)$.

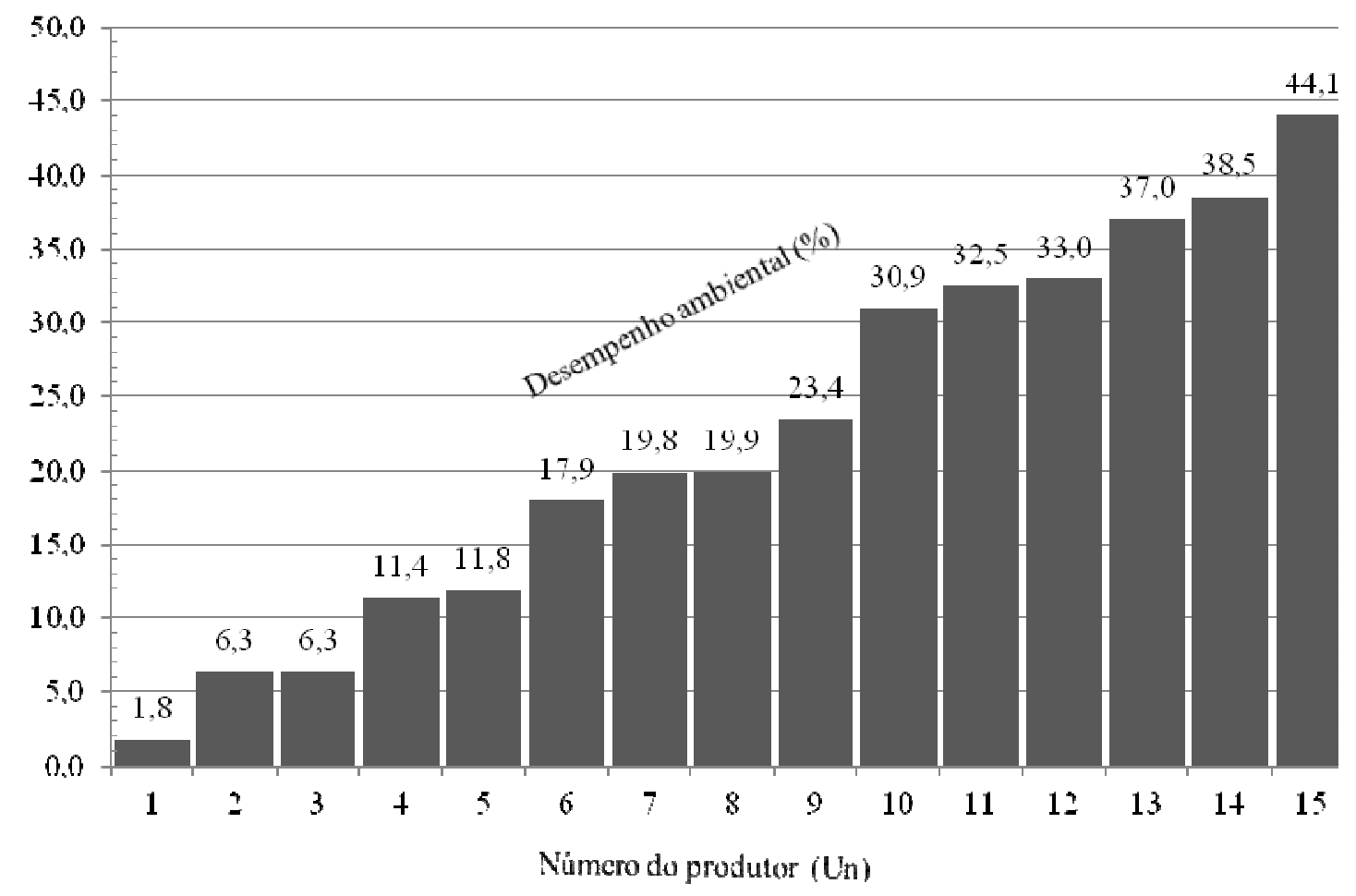

Figura 2: Aproximação aos coeficientes de desempenho ambiental das propriedades analisadas na amostra $n=15$, em Colorado do Oeste, Rondônia, em 2011.

Fonte: adaptado de Borges et al. (2013a).

Os dados apresentados na Figura 2 exibem que as nove primeiras propriedades de piscicultores entrevistados apresentaram desempenho 
ambientais crítico (inferior a 30,0\%). As outras cinco propriedades de piscicultores entrevistadas apresentaram desempenho ambiental péssimo (entre 30,0 e $50,0 \%$ ).

Esses resultados obtidos são semelhantes aos encontrados por Borges et al. (2013b) que, avaliando amostra de 20 aquicultores em pesquisa realizada no município de Ariquemes, estado de Rondônia, encontraram desempenho ambiental crítico nas 13 primeiras propriedades rurais avaliadas (inferior a $30,0 \%$ ). Seis propriedades rurais apresentaram desempenho ambiental péssimo (entre 30,0 e 50,0\%) e apenas uma propriedade rural apresentou desempenho ambiental adequado (entre 50 e 70\%).

Em termos gerais, a situação de desempenho ambiental não foi favorável a todas as propriedades piscícolas, independentemente da área de lâmina de água da propriedade, faltando aos produtores maior envolvimento com as questões ambientais. Foram detectados problemas de relações com a comunidade, segurança do trabalhador e relações com os mesmos, conservação de áreas protegidas, problemas no manejo de efluentes oriundos dos viveiros, disposição de insumos e resíduos, manejo de medicamentos e químicos e rastreabilidade.

\section{Conclusões}

Observando-se as percentagens de desmatamento anuais e o aumento sucessivo e intensificado em direção as áreas florestadas das terras na Amazônia Ocidental, se constata um panorama que necessita de empenhos emergenciais para restrição do desmatamento e retomada das áreas abandonadas em função dos danos causados pela baixa fertilidade do solo.

Estas extensões de desmatamentos têm proporcionado um processo de intensa centralização fundiária evidenciada pelo êxodo rural que têm prevalecido em Rondônia durante os últimos 35 anos. A população de Rondônia tem aumentado e migrado para as áreas urbanas ininterruptamente. Há, além disso, um pujante fluxo de migrantes em direção à frente de desmatamento, por meio do oferecimento de espaços nestas áreas, na maioria das vezes ignoradas pelos governos estaduais e federais.

O modelo de produção adotado atualmente pelo estado de Rondônia, de estimulação à piscicultura é extremamente agressivo às áreas de florestas de proteção, dada a necessidade de grande quantidade de água para a produção de peixes confinados. Como em grande parte os imóveis no estado de Rondônia foram instituídos tomando como fundamento áreas de 50 e 100 hectares, não obstante da reconcentração que essas terras vêm sofrendo, a produção de gado bovino de corte e leiteiro e a piscicultura continental acabam por avançar sobre a área de florestas protetoras. Alternativas para a produção que resguarde as florestas protetoras não tem sido alvo das políticas de ocupação e desenvolvimento para a região por nenhuma das esferas de governo. 
Qualquer que seja o intervalo instituído por princípio legal como floresta protetora, independentemente se existe ou não cobertura vegetal, localizada em área rural, necessita ser considerado intocável, com a ressalva dos casos de conveniência pública, interesse social e atividades de baixos impactos ambientais definidos pelo Conselho Nacional de Meio Ambiente (CONAMA).

Não é plausível que somente os produtores agropecuários, aí incluídos os produtores de peixes, sejam culpados pela não execução das leis ambientais, sobretudo, na destinação das áreas de florestas protetoras dos empreendimentos rurais motivo de reforma agrária no país. Desta maneira, não se segue o principal preceito que apoia toda a legislação ambiental, o de que todos têm direito a um meio ambiente equilibrado, bem de uso comum do povo e essencial à sadia qualidade de vida, como define o Artigo 225 da Constituição Federativa do Brasil de 1988. Adota-se nesse caso a cláusula capitalista de que as áreas do planeta devem ter exclusivamente sua destinação econômica afiançada, não havendo necessidade de compatibilização com as demais legislações, escapando assim, do conceito de sustentabilidade que devem considerar as questões como sociedade, meio ambiente e economia indissociáveis.

\section{AGRADECIMENTOS}

Ao Conselho Nacional de Desenvolvimento Científico e Tecnológico (CNPq), pelo apoio financeiro à pesquisa; à Universidade Federal de Lavras, por tornar possível o Pós-doutoramento do primeiro autor.

\section{REFERÊNCIAS}

BORGES, L.A.C. Aspectos técnicos e legais que fundamentam o estabelecimento das Áreas de Preservação Permanente (APP). 2008. $210 f$. Tese (Doutorado em Engenharia Florestal) - Curso de Pós-Graduação em Engenharia Florestal, Universidade Federal de Lavras. Disponível em: $<$ http://bdtd.ufla.br/tde busca/arquivo.php?codarquivo=1687>. Acesso em 10 jan. 2012.

BORGES, L.A.C. et al. Áreas de preservação permanente na legislação ambiental brasileira. Cienc. Rural, Santa Maria, v. 41, n. 7, julho 2011.

Disponível

em: $<$ http://www.scielo.br/scielo.php?script=sci arttext\&pid=s010384782011000700 $016 \&$ Ing $=$ en\&nrm=iso $>$. Acesso em: 15 jan. 2012. http://dx.doi.org/10.1590/s0103-84782011000700016.

BORGES, A.F. et al. Desempenho ambiental da piscicultura na amazônia ocidental brasileira. Global Science and Technology, v. 6, n. 1, 2013a.

BORGES, A.F. et al. Licensing and environmental performance of aquaculture in western amazon. Global Science and Technology, v. 6, n. 3, 2013b. 
BRASIL. Decreto Federal n. 23.793, de 23 de janeiro de 1934. Decreta o código florestal. Rio de Janeiro, DF, 1934. Disponível em: $<$ http://www.planalto.gov.br/ccivil 03/decreto/1930-1949/d23793.htm>. Acesso em: 15 jan. 2012.

BRASIL. Decreto Federal n. 24.643, de 10 de julho de 1934. Decreta o código das águas. Rio de Janeiro, DF, 1934. Disponível em: $<$ http://www.planalto.gov.br/ccivil 03/decreto/d24643.htm>. Acesso em: 15 jan. 2012.

BRASIL. Lei 4.771, de 15 de setembro de 1965. Instituiu o código florestal brasileiro. Brasília, DF, $1965 . \quad$ Disponível em: <http://www.planalto.gov.br/ccivil 03/leis/L4771.htm>.Acesso em: 15 jan. 2012.

BRASIL. Lei 5.727, de 4 de novembro de 1971. Dispõe sobre o Primeiro Plano Nacional de Desenvolvimento (PND), para o período de 1972 a 1974. Brasília, DF, 1971. Disponível em: <http://www.planalto.gov.br/ccivil 03/leis/19701979//5727.htm>. Acesso em: 14 jan. 2012.

BRASIL. Do meio ambiente: artigo 225. In: 1988. Brasília, DF, 1988. Cap.6. Disponível em: $<$ http://www.planalto.gov.br/ccivil 03/constituicao/constituicao.htm>. Acesso em: 15 jan. 2012.

BRASIL. Lei 9.433, de 8 de janeiro de 1997. Institui a política nacional de recursos hídricos. Brasília, DF, 1997. Disponível em: <http://www.planalto.gov.br/ccivil 03/leis/l9433.htm>. Acesso em: 15 jan. 2012.

BRASIL. Medida Provisória 2.166-67, de 24 de agosto de 2001. Altera os arts. 10, 40,14, 16 e 44, e acresce dispositivos à Lei n. 4.771 de 1965: código florestal. Brasília, DF, 2001. Disponível em: $<$ http://www.planalto.gov.br/ccivil 03/mpv/2166-67.htm>. Acesso em: 15 jan. 2012.

BRASIL. Lei 1.861, de 10 de janeiro de 2008. Dispõe, define e disciplina a piscicultura no estado de Rondônia. Porto Velho, RO, 2008. Disponível em: $<$ http://www.sedam.ro.gov.br/images/stories/psicultura/dlfe-157.pdf >. Acesso em: 15 jan. 2012.

CONAMA. Conselho Nacional de Meio Ambiente. Resolução n. 369, de 28 de março de 2006. Dispõe sobre os casos excepcionais, de utilidade pública, interesse social ou baixo impacto ambiental, que possibilitam a intervenção ou supressão de vegetação em Área de Preservação Permanente - APP. Brasília, DF, $2006 . \quad$ Disponível em: $<$ http://www.mma.gov.br/port/conama/legiabre.cfm?codlegi=489>. Acesso em: 20 jul. 2009.

CARRASCO, S. C. P. Diagnóstico do estado ambiental e elaboração de um modelo de gestão ambiental para a piscicultura do município de castilla la nueva, meta Colômbia. 2006. 160f. Tese (Doutorado em Engenharia de 
Produção) - Curso de Pós-Graduação em Engenharia de Produção, Universidade Federal de Santa Catarina. Disponível em:<http:// http://www.tede.ufsc.br/teses/peps4921.pdf>. Acesso em: 20 de janeiro de 2012.

ELER, M.N.; MILLANI, T.J. Métodos de estudos de sustentabilidade aplicados à aquicultura. R. Bras. Zootec., v.36, p.33-44, 2007. Disponível em:<http://www.revistasbz.org.br/scripts/revista/sbz1/Artigos/9004.pdf. Acesso em: 11 de julho de 2011. doi: http://dx.doi.org/10.1590/s151635982007001000004.

GTDS. Relatório Final. Universidade Federal de Rondônia. 2006.

SCHRÖDER, P.H. 2008. 120f. Análise espaço temporal no processo de ocupação do município de Corumbiara, Rondônia. Dissertação (Mestrado em Geografia) - Curso de Pós-Graduação em Geografia, Universidade Federal de Santa Catarina. Disponível em: <http://www.tede.ufsc.br/teses/pgcn0336d.pdf.>. Acesso em: 14 de janeiro de 2012.

SILVA, A.A; MIZIARA, F. Avanço do setor sucroalcooleiro e expansão da fronteira agrícola em Goiás. Revista Pesq. Agropec. Trop., Goiânia, v. 41, n. 3 , p. 399-407, jul./set. $2011 . \quad$ Disponível em: <http://www.revistas.ufg.br/index.php/pat/article/view/11054/9648>. Acesso em: 14 jan. 2012. doi: 10.5216/pat.v41i3.11054.

SILVA, M. Avaliação por imagens sar da reserva legal dos assentamentos no estado de Rondônia aplicando o código florestal brasileiro. 2008. $108 \mathrm{f}$. Dissertação (Mestrado em Engenharia Civil) - Curso de pós-graduação em Engenharia Civil, Universidade Federal de Santa Catarina. Disponível em: $<$ http://www.tede.ufsc.br/teses/pecv0522-d.pdf >. Acesso em: 14 jan. 2012. 